\title{
RESEARCH
}

Open Access

\section{Global profiling of prolactin-modulated transcripts in breast cancer in vivo}

Takahiro Sato, Thai H Tran, Amy R Peck, Chengbao Liu, Adam Ertel, Justin Lin, Lynn M Neilson and Hallgeir Rui ${ }^{*}$

\begin{abstract}
Background: Prolactin (PRL) is essential for normal mammary gland development. PRL promotes mammary tumor formation in rodents and elevated serum prolactin is associated with increased risk of estrogen-receptor positive breast cancer in women. On the other hand, PRL may also exert pro-differentiation effects and act to suppress invasive features of established breast cancer. Previously published limited global transcript profiling analyses of prolactin-regulated gene expression in human breast cancer cells have exclusively been performed in vitro. The present study aimed to shed new light on how PRL modulates estrogen receptor (ER)-positive breast cancer through global transcript profiling of a human breast cancer xenograft model in vivo.
\end{abstract}

Methods: The prolactin-responsive human T47D breast cancer cell line was xenotransplanted into nude mice and global transcript profiling was carried out following treatment with or without human PRL for $48 \mathrm{~h}$. A subset of PRL-modulated transcripts was further validated using QRT-PCR and immunohistochemistry.

Results: The in vivo analyses identified 130 PRL-modulated transcripts, 75 upregulated and 55 downregulated, based on fold change $>1.6$ and P-value $<0.05$. From this initial panel of transcripts, a subset of 18 transcripts with established breast cancer-relevance were selected and validated by qRT-PCR. Some but not all of the transcripts were also PRL-modulated in vitro. The selected PRL-modulated transcripts were tested for dependence on Stat5, Jak1 or Jak2 activation, and for co-regulation by $17 \beta$-estradiol (E2). The protein encoded by one of the PRL-regulated transcripts, PTHrP, was examined in a panel of 92 human breast cancers and found by in situ quantitative immunofluorescence analysis to be highly positively correlated with nuclear localized and tyrosine phosphorylated Stat5. Gene Ontology analysis revealed that PRL-upregulated genes were enriched in pathways involved in differentiation. Finally, a gene signature based on PRL-upregulated genes was associated with prolonged relapse-free and metastasis-free survival in breast cancer patients.

Conclusions: This global analysis identified and validated a panel of PRL-modulated transcripts in an ER-positive human breast cancer xenotransplant model, which may have value as markers of relapse-free and metastasis-free survival. Gene products identified in the present study may facilitate ongoing deciphering of the pleiotropic effects of PRL on human breast cancer.

Keywords: Breast cancer, Prolactin, Stat5

\footnotetext{
* Correspondence: hallgeir.rui@jefferson.edu

Department of Cancer Biology, Kimmel Cancer Center, Thomas Jefferson University, Philadelphia, PA, USA
}

\section{Biomed Central}

(c) 2013 Sato et al.; licensee BioMed Central Ltd. This is an Open Access article distributed under the terms of the Creative Commons Attribution License (http://creativecommons.org/licenses/by/2.0), which permits unrestricted use, distribution, and reproduction in any medium, provided the original work is properly cited. 


\section{Background}

Prolactin (PRL) is a pituitary hormone that is critical for normal mammary gland development by promoting proliferative expansion of the secretory alveolar cell compartment during pregnancy and for terminal differentiation of these milk-producing cells during lactation. Prolactin is also strongly implicated in breast cancer. On one hand, accumulating evidence suggests that PRL promotes breast cancer initiation and growth. In vivo, PRL over-expressing transgenic mice have an increased incidence of mammary tumors [1], while PRL knock-out mice have a reduced incidence of mammary tumors [2]. In women, elevated PRL is associated with increased risk of ER-positive breast cancer $[3,4]$. Furthermore, $70-95 \%$ of human breast cancers express PRL receptor (PRLR) [5,6], and many breast cancer cell lines express high levels of PRLR with evidence of proliferative or survival responses to PRL in vitro $[7,8]$. PRL was also able to enhance 17ß-Estradiol (E2) dependent proliferation of breast cancer cells [9-11]. On the other hand, evidence suggests that PRL acts to preserve cellular differentiation of breast cancer. Stat5 transcription factors, principal mediators of PRL effects [12,13], are frequently inactivated during metastatic progression in clinical breast cancer specimens, and loss of Stat 5 signaling is associated with unfavorable prognosis and increased risk of anti-estrogen therapy failure [14-17]. In experimental breast cancer models, activation of Stat 5 increased cell surface E-cadherin expression, induced homotypic cell clustering, and reduced invasion through Matrigel $[18,19]$. Restoration of PRL-Stat5 signaling in the mesenchymallike MDA-MB-231 cells reverted their invasive phenotype, while blocking autocrine PRL signaling in the epithelial T47D cell line was associated with EMT and enhanced invasive properties [20]. In T47D cells, PRL also blocked progestin-induction of a tumor-initiating CK5-positive cell population through a mechanism that involved PRLsuppression of progestin-induced BCL6 [21].

Due to the importance of PRL in breast cancer growth and differentiation, identifying genes regulated by the PRL-Stat5 pathway may provide new insights into the pleiotropic effects of PRL in breast cancer. Several studies have identified genes regulated by PRL in the normal mouse mammary gland [22-26], but only a limited number of studies have been carried out in human breast cancer cells. More importantly, global profiling for PRLmodulated gene expression in human breast cancer in vivo has not been reported. One in vitro study identified genes regulated by PRL, E2, and PRL + E2 in cultured ER-positive T47D cells using genome-wide transcript profiling [9], while a second in vitro study used subtractive hybridization to identify PRL-regulated genes in the ER-negative, Her2-overexpressing SKBR3 cell line [27]. However, neither study confirmed whether the identified transcripts were regulated by Stat 5 or remained PRL-modulated in vivo. Work from our laboratory used selective overexpression of either Stat5a or Stat5b in the ER-positive MCF-7 human breast cancer cell line in vitro followed by PRL exposure to explore differences in Stat5a and Stat5b regulated transcripts on the Affymetrix platform, but this study also failed to confirm any of the modulated transcripts by qRT-PCR or validate the data in vivo [17]. An additional very recent study also examined the MCF-7 model and reported PRL regulated genes, as well as genes uniquely modulated through activation of the PRLR transactivation domain [28], but the investigators did not examine whether the identified transcripts were regulated by Stat5 or remained PRL-modulated in vivo.

Based on observed differences in hormone-modulated transcriptional programs in human cancer cells in vitro and in vivo [29], PRL-modified transcripts identified in an in vivo environment are expected to be more clinically relevant than transcripts modulated in cells cultured on plastic. The present study reports a panel of $130 \mathrm{PRL}$ regulated transcripts in the human T47D breast cancer xenotransplant model in estrogenized nude mice. T47D xenografts were established in nude mice and mice were exposed to human PRL or saline for $48 \mathrm{~h}$ before RNA isolation from tumor extracts. Of the 130 transcripts, 75 were up-regulated and 55 were down-regulated. Modulated transcripts were identified based on fold change $(>1.6)$ and P-value $(<0.05)$. From this initial transcript set, 18 transcripts were selected based on known breast cancer relevance for validation by qRT-PCR. Many but not all of the in vivo validated transcripts were PRLmodulated in vitro. We also determined the dependence of PRL-modulated transcripts on Stat5, Jak1 or Jak2, and whether individual modulated genes are co-regulated by PRL and E2. One of the PRL-modulated genes identified, parathyroid hormone-related peptide (PTHrP), was found by fluorescence-based quantitative immunohistochemistry to positively correlate with levels of nuclear localized, tyrosine phosphorylated Stat5 (Nuc-pYStat5) at the protein level in clinical human breast cancer specimens. Gene Ontology (GO) analysis of PRL-upregulated genes demonstrated enrichment in differentiation pathways. Finally, a gene signature based on PRL-upregulated genes was associated with prolonged relapse-free and metastasis-free survival in human breast cancer patients. Studies are ongoing to determine how modulation of these genes, including PTHrP, may mediate PRL effects in breast cancer.

\section{Results}

Global transcript profiling reveals novel PRL-modulated genes in human T47D breast cancer xenotransplants Global gene expression analysis was performed using the hormone receptor positive T47D xenotransplant model. Tumor-bearing nude mice received either human prolactin 
$(\mathrm{N}=10)$ or vehicle $(\mathrm{N}=10)$ subcutaneously every $12 \mathrm{~h}$ for $48 \mathrm{~h}$. Representative images of T47D xenograft tissues display robust tyrosine phosphorylated Stat5 (pY-Stat5) staining in response to PRL (Figure 1A). For the microarray analyses, RNA isolated from individual tumors was pooled into 3 groups from PRL injected mice and 3 groups from control mice, with each group containing RNA from tumors of 3 or 4 mice. Global profiling on the Affymetrix U133 platform identified 75 upregulated transcripts (Table 1) and 55 down-regulated transcripts (Table 2) based on P-values $(<0.05)$ and fold difference $(>1.6)$. From this panel, 18 transcripts were selected for further analysis based on established breast cancer relevance (Table 3). $\mathrm{CISH}$ was induced by PRL and included in subsequent analyses as a positive control, since CISH is an established STAT5 target gene [30]. Based on the microarray data of this panel of 18 transcripts, 15 were upregulated and three were down-regulated 1.6-fold.

\section{qRT-PCR validation of 18 candidate prolactin modulated} genes

To validate the data from the global microarray analysis, qRT-PCR analysis was carried out on the 18 selected genes using the same xenograft RNA samples that were used for the microarray-based profiling. Of the upregulated transcripts, 12 out of 15 transcripts were confirmed to be upregulated by qRT-PCR >1.6-fold, whereas upregulation of GADD45A, ERAP1, FGFR2 was not confirmed by qRTPCR. Among the selected three down-regulated transcripts, BCL6 was confirmed down-regulated $>1.6$ fold by qRT-PCR, whereas FLT4 and SOX4 were down-regulated 1.3-fold and 1.6-fold, respectively, by qRT-PCR analysis (Figure 1B).

We then identified PRL-modulated transcripts in T47D xenotransplants that were also modulated by PRL T47D cells in vitro. Immunoblot analysis of T47D cells cultured in vitro displayed robust pY-Stat5 in response to $10 \mathrm{nM}$ human PRL for $24 \mathrm{~h}$ (Figure 1C). qRT-PCR analysis of mRNA extracted from T47D cells treated with or without PRL for $24 \mathrm{~h}$ established that 9 of the 12 qRT-PCR validated upregulated transcripts also were upregulated over 1.6-fold in vitro, while three transcripts, CCR6, AMIGO2, and DUSP4 were not modulated by PRL in vitro (Figure 1D). Transcripts for GADD45A, ERAP1, FGFR2, which were not confirmed by qRT-PCR analysis of transcripts in vivo, remained unmodulated in vitro (Figure 1D).
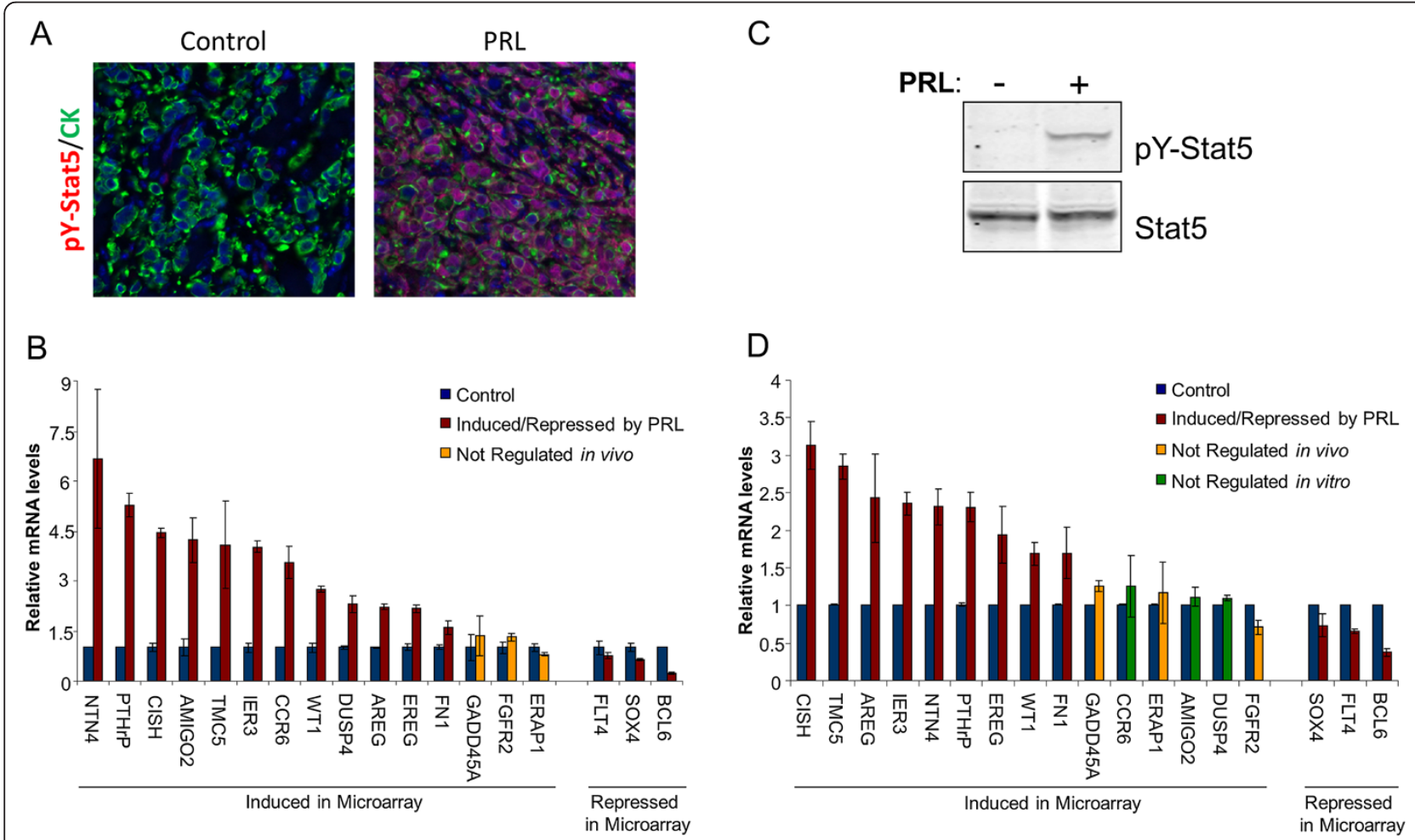

Figure 1 qRT-PCR validation of $\mathbf{1 8}$ candidate prolactin modulated transcripts. (A) Representative images of T47D xenografts treated with or without PRL for $48 \mathrm{~h}$ and stained with tyrosine phosphorylated Stat5 (pY-Stat5)(red) or DAPI (blue) using immunofluorescence. (B) RNA isolated from T47D xenografts were tested for 18 breast cancer relevant genes using qRT-PCR analysis. Bars represent an average of fold change from 3 independent xenograft RNA samples. (C) Immunoblot of pY-Stat5 and Stat5 in T47D cells grown in vitro and placed in serum starvation media for $24 \mathrm{~h}$ before treatment with vehicle or $10 \mathrm{nM} \mathrm{PRL}$ for $24 \mathrm{~h}$. (D) RNA isolated from T47D cells grown in vitro were tested for the same 18 breast cancer relevant genes using qRT-PCR analysis. Bars represent an average of fold change from 3 independent experiments. 
Table 1 Upregulated genes from microarray with fold change $>1.6$ and $p<0.05$

\begin{tabular}{|c|c|c|c|c|}
\hline & Unigene & Symbol & Gene descriptor & Fold change \\
\hline 1 & Hs.89626 & PTHrP & parathyroid hormone-like hormone & 11.9 \\
\hline 2 & Hs.473539 & $\mathrm{BACH} 1$ & BTB and CNC homology 1, basic leucine zipper transcription factor 1 & 5.2 \\
\hline 3 & Hs.46468 & CCR6 & chemokine (C-C motif) receptor 6 & 4.9 \\
\hline 4 & Hs.314676 & $\mathrm{ITCH}$ & itchy homolog E3 ubiquitin protein ligase & 4.2 \\
\hline 5 & Hs. 150744 & INVS & inversin & 3.8 \\
\hline 6 & Hs.387222 & NEK6 & NIMA (never in mitosis gene a)-related kinase 6 & 3.8 \\
\hline 7 & Hs.76095 & IER3 & immediate early response 3 & 3.4 \\
\hline 8 & Hs. 121520 & AMIGO2 & amphoterin induced gene 2 & 3.3 \\
\hline 9 & Hs.115263 & EREG & epiregulin & 3.2 \\
\hline 10 & Hs.436186 & ERAP1 & type 1 tumor necrosis factor receptor shedding aminopeptidase regulator & 3.0 \\
\hline 11 & Hs.99037 & CTEN & C-terminal tensin-like & 3.0 \\
\hline 12 & Hs.252855 & $\mathrm{MFI} 2$ & antigen p97 (melanoma associated) & 2.9 \\
\hline 13 & Hs.439658 & MGC4796 & Ser/Thr-like kinase & 2.8 \\
\hline 14 & Hs.417962 & DUSP4 & dual specificity phosphatase 4 & 2.7 \\
\hline 15 & Hs. 8257 & $\mathrm{CISH}$ & cytokine inducible $\mathrm{SH}$-containing protein & 2.6 \\
\hline 16 & Hs.660427 & PAR5 & Prader-Willi/Angelman syndrome-5 & 2.6 \\
\hline 17 & Hs.279887 & AIPL1 & aryl hydrocarbon receptor interacting protein-like 1 & 2.6 \\
\hline 18 & Hs. 145807 & TMC5 & transmembrane channel-like 5 & 2.5 \\
\hline 19 & Hs.512708 & TGM2 & transglutaminase 2 & 2.4 \\
\hline 20 & Hs.270833 & AREG & amphiregulin (schwannoma-derived growth factor) & 2.4 \\
\hline 21 & Hs.170623 & FGD6 & FYVE, RhoGEF and PH domain containing 6 & 2.3 \\
\hline 22 & Hs.418138 & FN1 & fibronectin 1 & 2.3 \\
\hline 23 & Hs. 102541 & NTN4 & netrin 4 & 2.2 \\
\hline 24 & Hs.354906 & RAB39 & RAB39, member RAS oncogene family & 2.2 \\
\hline 25 & Hs.443906 & EGLN3 & egl nine homolog 3 (C. elegans) & 2.2 \\
\hline 26 & Hs. 149156 & GLDC & glycine dehydrogenase & 2.2 \\
\hline 27 & Hs. 1145 & WT1 & Wilms tumor 1 & 2.1 \\
\hline 28 & Hs. 25220 & LARGE & like-glycosyltransferase & 2.1 \\
\hline 29 & Hs.282557 & $C P$ & ceruloplasmin (ferroxidase) & 2.0 \\
\hline 30 & Hs.78909 & ZFP36L2 & zinc finger protein $36, \mathrm{C} 3 \mathrm{H}$ type-like 2 & 2.0 \\
\hline 31 & Hs.413297 & RGS16 & regulator of G-protein signalling 16 & 2.0 \\
\hline 32 & Hs.182454 & NYREN18 & NEDD8 ultimate buster-1 & 2.0 \\
\hline 33 & Hs.96125 & $\mathrm{RCP}$ & Rab coupling protein & 2.0 \\
\hline 34 & Hs.308028 & TMEM17 & transmembrane protein 17 & 2.0 \\
\hline 35 & Hs.21894 & PPM1H & protein phosphatase $1 \mathrm{H}$ (PP2C domain containing) & 2.0 \\
\hline 36 & Hs.240395 & KCNK6 & potassium channel, subfamily K, member 6 & 1.9 \\
\hline 37 & Hs.36563 & B7-H4 & immune costimulatory protein $\mathrm{B} 7-\mathrm{H} 4$ & 1.9 \\
\hline 38 & Hs.27345 & RNGTT & RNA guanylyltransferase and 5'-phosphatase & 1.9 \\
\hline 39 & Hs. 144287 & HEY2 & hairy/enhancer-of-split related with YRPW motif 2 & 1.8 \\
\hline 40 & Hs.269857 & HRB2 & HIV-1 rev binding protein 2 & 1.8 \\
\hline 41 & Hs.387871 & TNFSF10 & tumor necrosis factor (ligand) superfamily, member 10 & 1.8 \\
\hline 42 & Hs.80409 & GADD45A & growth arrest and DNA-damage-inducible, alpha & 1.8 \\
\hline 43 & Hs.134742 & FAM20C & family with sequence similarity 20 , member $C$ & 1.8 \\
\hline 44 & Hs.274701 & TK2 & thymidine kinase 2, mitochondrial & 1.8 \\
\hline
\end{tabular}


Table 1 Upregulated genes from microarray with fold change $>1.6$ and $\mathbf{p}<0.05$ (Continued)

\begin{tabular}{|c|c|c|c|c|}
\hline 45 & Hs.55610 & SLC30A1 & solute carrier family 30 (zinc transporter), member 1 & 1.8 \\
\hline 46 & Hs.82173 & TIEG & TGFB inducible early growth response & 1.8 \\
\hline 47 & Hs.404081 & FGFR2 & fibroblast growth factor receptor 2 & 1.8 \\
\hline 48 & Hs.31218 & SCAMP1 & secretory carrier membrane protein 1 & 1.8 \\
\hline 49 & Hs.350470 & TFF1 & trefoil factor 1 & 1.8 \\
\hline 50 & Hs.95655 & SECTM1 & secreted and transmembrane 1 & 1.8 \\
\hline 51 & Hs.902 & NF2 & neurofibromin 2 & 1.7 \\
\hline 52 & Hs.310640 & $\mathrm{T} 2 \mathrm{BP}$ & TRAF2 binding protein & 1.7 \\
\hline 53 & Hs.252550 & TNIK & TRAF2 and NCK interacting kinase & 1.7 \\
\hline 54 & Hs.6838 & ARHE & ras homolog gene family, member $\mathrm{E}$ & 1.7 \\
\hline 55 & Hs.418062 & B3GALT3 & betaGlcNAc beta 1,3-galactosyltransferase, polypeptide 3 & 1.7 \\
\hline 56 & Hs.270411 & PLEKHC1 & pleckstrin homology domain containing, family $\mathrm{C}$ member 1 & 1.7 \\
\hline 57 & Hs.647388 & ARHGDIG & Rho GDP dissociation inhibitor (GDI) gamma & 1.7 \\
\hline 58 & Hs.202453 & MYC & v-myc myelocytomatosis viral oncogene homolog (avian) & 1.6 \\
\hline 59 & Hs.110488 & CHSY1 & carbohydrate (chondroitin) synthase 1 & 1.6 \\
\hline 60 & Hs.9795 & ACOX2 & acyl-Coenzyme A oxidase 2, branched chain & 1.6 \\
\hline 61 & Hs.158357 & UNC5CL & unc-5 homolog C (C. elegans)-like & 1.6 \\
\hline 62 & Hs.441972 & IFNT1 & interferon tau-1 & 1.6 \\
\hline 63 & Hs.221889 & CSDA & cold shock domain protein $\mathrm{A}$ & 1.6 \\
\hline 64 & Hs.333503 & RNF38 & ring finger protein 38 & 1.6 \\
\hline 65 & Hs.203581 & DDX54 & DEAD (Asp-Glu-Ala-Asp) box polypeptide 54 & 1.6 \\
\hline 66 & Hs.345226 & ZNF563 & zinc finger protein 563 & 1.6 \\
\hline 67 & Hs.30991 & ANKRD6 & ankyrin repeat domain 6 & 1.6 \\
\hline 68 & Hs.4113 & AHCYL1 & S-adenosylhomocysteine hydrolase-like 1 & 1.6 \\
\hline 69 & Hs.416077 & SEMA4B & sema domain & 1.6 \\
\hline 70 & Hs.7378 & PHLDB2 & pleckstrin homology-like domain, family B, member 2 & 1.6 \\
\hline 71 & Hs.369063 & $\mathrm{ZIC2}$ & Zic family member 2 (odd-paired homolog, Drosophila) & 1.6 \\
\hline 72 & Hs.515284 & ZNF505 & zinc finger protein 505 & 1.6 \\
\hline 73 & Hs.426511 & MIPOL1 & mirror-image polydactyly 1 & 1.6 \\
\hline 74 & Hs.108966 & PIP5K2A & phosphatidylinositol-4-phosphate 5-kinase, type II, alpha & 1.6 \\
\hline 75 & Hs.432607 & PSMB2 & proteasome (prosome, macropain) subunit, beta type, 2 & 1.6 \\
\hline
\end{tabular}

Out of the three selected down-regulated transcripts, BCL6 maintained PRL induced down-regulation of $>1.6-$ fold in vitro, whereas FLT4 and SOX4 again were reproducibly down-regulated but only 1.5 -fold and 1.4-fold respectively $(\mathrm{p}<0.05)$ (Figure $1 \mathrm{D})$. Since these values were only marginally lower than 1.6, we elected to keep FLT4 and SOX4 in the subsequent analyses. In subsequent experiments we focused on the set of 12 transcripts out of original selected panel of 18 transcripts that were PRLresponsive both in vivo and in vitro.

\section{Stat5 regulates novel PRL-modulated transcripts}

PRL activates multiple signaling pathways in breast cancer cells [31], with Stat5 constituting a principal mediator of PRL actions during development and differentiation of the mammary gland [32]. To determine whether the observed PRL-modulated transcripts were regulated through the Stat 5 pathway, we overexpressed Stat $5 \mathrm{a}, \mathrm{Stat} 5 \mathrm{~b}$, or a dominant-negative Stat5a/b (DNStat5) in T47D cells using adenoviral gene delivery, and treated cells with or without PRL for $24 \mathrm{~h}$. Immunoblot analysis of total cell lysates verified over-expression of the correct Stat 5 variants and robust PRL-induction of pY-Stat5 in cells following adenoviral gene delivery (Figure 2A). The overexpression was sufficiently high that basal levels of Stat5 were not detectable without further exposure of the blots (not shown). qRT-PCR analysis revealed that DNStat5 blocked PRL induction of each of the 9 upregulated transcripts. PRL induction of most of these 9 transcripts were further enhanced by overexpression of Stat $5 \mathrm{a}$ or Stat $5 \mathrm{~b}$, either basal 
Table 2 Downregulated genes from microarray with fold change $>-1.6$ and $p<0.05$

\begin{tabular}{|c|c|c|c|c|}
\hline & Unigene & Symbol & Gene descriptor & Fold Change \\
\hline 1 & Hs.275464 & KLK10 & kallikrein 10 & -3.3 \\
\hline 2 & Hs.307030 & KRTAP1-5 & keratin associated protein 1-5 & -3.3 \\
\hline 3 & Hs.282233 & MLLT6 & myeloid/lymphoid leukemia translocated to, 6 & -3.2 \\
\hline 4 & Hs.78518 & NPR2 & natriuretic peptide receptor $\mathrm{B} /$ guanylate cyclase $\mathrm{B}$ & -2.8 \\
\hline 5 & Hs.155024 & BCL6 & B-cell CLL/lymphoma 6 & -2.8 \\
\hline 6 & Hs.90800 & MMP16 & matrix metalloproteinase 16 (membrane-inserted) & -2.5 \\
\hline 7 & Hs.87539 & ALDH3B2 & aldehyde dehydrogenase 3 family, member B2 & -2.4 \\
\hline 8 & Hs.144906 & METAP2 & methionyl aminopeptidase 2 & -2.3 \\
\hline 9 & Hs.440455 & ALAS2 & aminolevulinate, delta-, synthase 2 & -2.2 \\
\hline 10 & Hs.266175 & PAG & phosphoprotein associated with glycosphingolipid-enriched microdomains & -2.2 \\
\hline 11 & Hs.435947 & RBM15 & RNA binding motif protein 15 & -2.2 \\
\hline 12 & Hs.233325 & HFE & hemochromatosis & -2.1 \\
\hline 13 & Hs.443012 & SEMA6A & sema domain,transmembrane domain(TM),and cytoplasmic domain,(semaphorin)6A & -2.0 \\
\hline 14 & Hs.357901 & SOX4 & SRY (sex determining region Y)-box 4 & -2.0 \\
\hline 15 & Hs.415048 & FLT4 & fms-related tyrosine kinase 4 & -2.0 \\
\hline 16 & Hs.380833 & IGFBP5 & insulin-like growth factor binding protein 5 & -1.9 \\
\hline 17 & Hs.444881 & CRAMP1L & Crm, cramped-like (Drosophila) & -1.9 \\
\hline 18 & Hs.398124 & DNAH5 & dynein, axonemal, heavy polypeptide 5 & -1.9 \\
\hline 19 & Hs.79025 & SNRK & SNF-1 related kinase & -1.9 \\
\hline 20 & Hs.432121 & PRDX2 & peroxiredoxin 2 & -1.9 \\
\hline 21 & Hs.22370 & NEXN & nexilin ( $F$ actin binding protein) & -1.9 \\
\hline 22 & Hs.144914 & GNMT & glycine N-methyltransferase & -1.9 \\
\hline 23 & Hs.21446 & CENTB5 & centaurin, beta 5 & -1.9 \\
\hline 24 & Hs.58103 & AKAP9 & A kinase (PRKA) anchor protein (yotiao) 9 & -1.8 \\
\hline 25 & Hs.387385 & SMURF2 & E3 ubiquitin ligase SMURF2 & -1.8 \\
\hline 26 & Hs.324470 & ADD3 & adducin 3 (gamma) & -1.8 \\
\hline 27 & Hs.348387 & GSTM4 & glutathione S-transferase M4 & -1.8 \\
\hline 28 & Hs.58419 & TARSH & target of Nesh-SH3 & -1.7 \\
\hline 29 & Hs.174051 & SNRP70 & small nuclear ribonucleoprotein 70 kDa polypeptide (RNP antigen) & -1.7 \\
\hline 30 & Hs.211601 & MAP3K12 & mitogen-activated protein kinase kinase kinase 12 & -1.7 \\
\hline 31 & Hs.23964 & SAP18 & sin3-associated polypeptide, $18 \mathrm{kDa}$ & -1.7 \\
\hline 32 & Hs.380929 & LDHD & lactate dehydrogenase $\mathrm{D}$ & -1.7 \\
\hline 33 & Hs.390568 & ZNF585A & zinc finger protein $585 \mathrm{~A}$ & -1.7 \\
\hline 34 & Hs.241305 & TRIM16 & tripartite motif-containing 16 & -1.7 \\
\hline 35 & Hs.403933 & $\mathrm{FBXO32}$ & F-box only protein 32 & -1.7 \\
\hline 36 & Hs.434756 & AP2E & adaptor-related protein complex 2, epsilon subunit & -1.7 \\
\hline 37 & Hs.173894 & CSF1 & colony stimulating factor 1 (macrophage) & -1.6 \\
\hline 38 & Hs. 104555 & NPFF & neuropeptide FF-amide peptide precursor & -1.6 \\
\hline 39 & Hs.307015 & KRTAP4-14 & keratin associated protein 4-14 & -1.6 \\
\hline 40 & Hs.301961 & GSTM1 & glutathione S-transferase M1 & -1.6 \\
\hline 41 & Hs.307915 & $\mathrm{ABCC} 4$ & ATP-binding cassette, sub-family C (CFTR/MRP), member 4 & -1.6 \\
\hline 42 & Hs.512000 & GP1BB & glycoprotein Ib (platelet), beta polypeptide & -1.6 \\
\hline 43 & Hs.446297 & ZNF498 & zinc finger protein 498 & -1.6 \\
\hline 44 & Hs.120396 & FRMD4 & FERM domain containing 4 & -1.6 \\
\hline
\end{tabular}


Table 2 Downregulated genes from microarray with fold change $>-1.6$ and $\mathbf{p}<0.05$ (Continued)

\begin{tabular}{lllll}
\hline 45 & Hs.222901 & GRIK4 & glutamate receptor, ionotropic, kainate 4 & -1.6 \\
46 & Hs.464896 & ZNF397 & zinc finger protein 397 & -1.6 \\
47 & Hs.16232 & CNKSR1 & connector enhancer of kinase suppressor of Ras 1 & -1.6 \\
48 & Hs.255526 & DTNA & dystrobrevin, alpha & -1.6 \\
49 & Hs.107203 & PLAC2 & placenta-specific 2 & -1.6 \\
50 & Hs.9029 & KRT23 & keratin 23 (histone deacetylase inducible) & -1.6 \\
51 & Hs.91753 & SMPD3 & sphingomyelin phosphodiesterase 3, neutral membrane (neutral sphingomyelinase II) & -1.6 \\
52 & Hs.331555 & SPINK5 & serine protease inhibitor, Kazal type 5 & -1.6 \\
53 & Hs.391858 & TIA1 & TIA1 cytotoxic granule-associated RNA binding protein & -1.6 \\
54 & Hs.109122 & MPP5 & membrane protein, palmitoylated 5 (MAGUK p55 subfamily member 5) & -1.6 \\
55 & Hs.445072 & ARGBP2 & Arg/Abl-interacting protein ArgBP2 & -1.6 \\
\hline
\end{tabular}

or PRL-induced (Figure 2B). Although levels of PRLinduced CISH and WT1 transcripts did not rise further by Stat 5 overexpression, PRL-induction of both transcripts was effectively abrogated by DNStat 5 , thus supporting Stat5-mediated regulation of these genes. Stat5 overexpression also enhanced down-regulation of both SOX4 and FLT4. The ERAP1 transcript was included as a negative control since it was not regulated by PRL as shown in Figure 1. Stat $5 \mathrm{a}$, Stat $5 \mathrm{~b}$, or DNStat 5 overexpression had no effect on ERAP1 transcript levels, indicating that enhancement of PRL-induction detected for the other transcripts is specific (Figure 2). BCL6 was omitted from this analysis since we have published this separately [33].
Jak2 and Jak1 are critical for PRL gene regulation in T47D breast cancer cells

Conditional gene knock-out in mice demonstrated that Jak2 is the key Stat5 tyrosine kinase in breast epithelial cells during and outside of pregnancy and lactation [34]. However, we have reported that in human breast cancer cell lines Jak1 is also recruited in a Jak2-dependent manner for maximal PRL-activation of Stat5 and other signaling mediators [31]. To determine whether PRL-recruitment of Jak1 was required for maximal modulation of PRL-regulated transcripts, T47D cells were infected with lentivirus carrying shRNAs targeting either Jak1 or Jak2 followed by treatment with or without PRL for $24 \mathrm{~h}$. Jak1 shRNA was effective and selective, as judged by marked down-

Table $3 \mathbf{1 8}$ genes chosen for further study based on breast cancer relevance

\begin{tabular}{|c|c|c|c|c|}
\hline & Unigene & Symbol & Gene descriptor & Fold Change \\
\hline 1 & Hs.89626 & PTHrP & parathyroid hormone-like hormone & 11.9 \\
\hline 2 & Hs.46468 & CCR6 & chemokine (C-C motif) receptor 6 & 4.9 \\
\hline 3 & Hs.76095 & IER3 & immediate early response 3 & 3.4 \\
\hline 4 & Hs.121520 & AMIGO2 & amphoterin induced gene 2 & 3.3 \\
\hline 5 & Hs.115263 & EREG & epiregulin & 3.2 \\
\hline 6 & Hs.436186 & ERAP1 & type 1 tumor necrosis factor receptor shedding aminopeptidase regulator & 3.0 \\
\hline 7 & Hs.417962 & DUSP4 & dual specificity phosphatase 4 & 2.7 \\
\hline 8 & Hs.8257 & $\mathrm{ClSH}$ & cytokine inducible SH2-containing protein & 2.6 \\
\hline 9 & Hs.145807 & TMC5 & transmembrane channel-like 5 & 2.5 \\
\hline 10 & Hs.270833 & AREG & amphiregulin (schwannoma-derived growth factor) & 2.4 \\
\hline 11 & Hs.418138 & FN1 & fibronectin 1 & 2.3 \\
\hline 12 & Hs.102541 & NTN4 & netrin 4 & 2.2 \\
\hline 13 & Hs.1145 & WT1 & Wilms tumor 1 & 2.1 \\
\hline 14 & Hs.80409 & GADD45A & growth arrest and DNA-damage-inducible, alpha & 1.8 \\
\hline 15 & Hs.404081 & FGFR2 & fibroblast growth factor receptor 2 & 1.8 \\
\hline 16 & Hs.155024 & BCL6 & B-cell CLL/lymphoma 6 & -2.8 \\
\hline 17 & Hs.357901 & SOX4 & SRY (sex determining region Y)-box 4 & -2.0 \\
\hline 18 & Hs.415048 & FLT4 & fms-related tyrosine kinase 4 & -2.0 \\
\hline
\end{tabular}




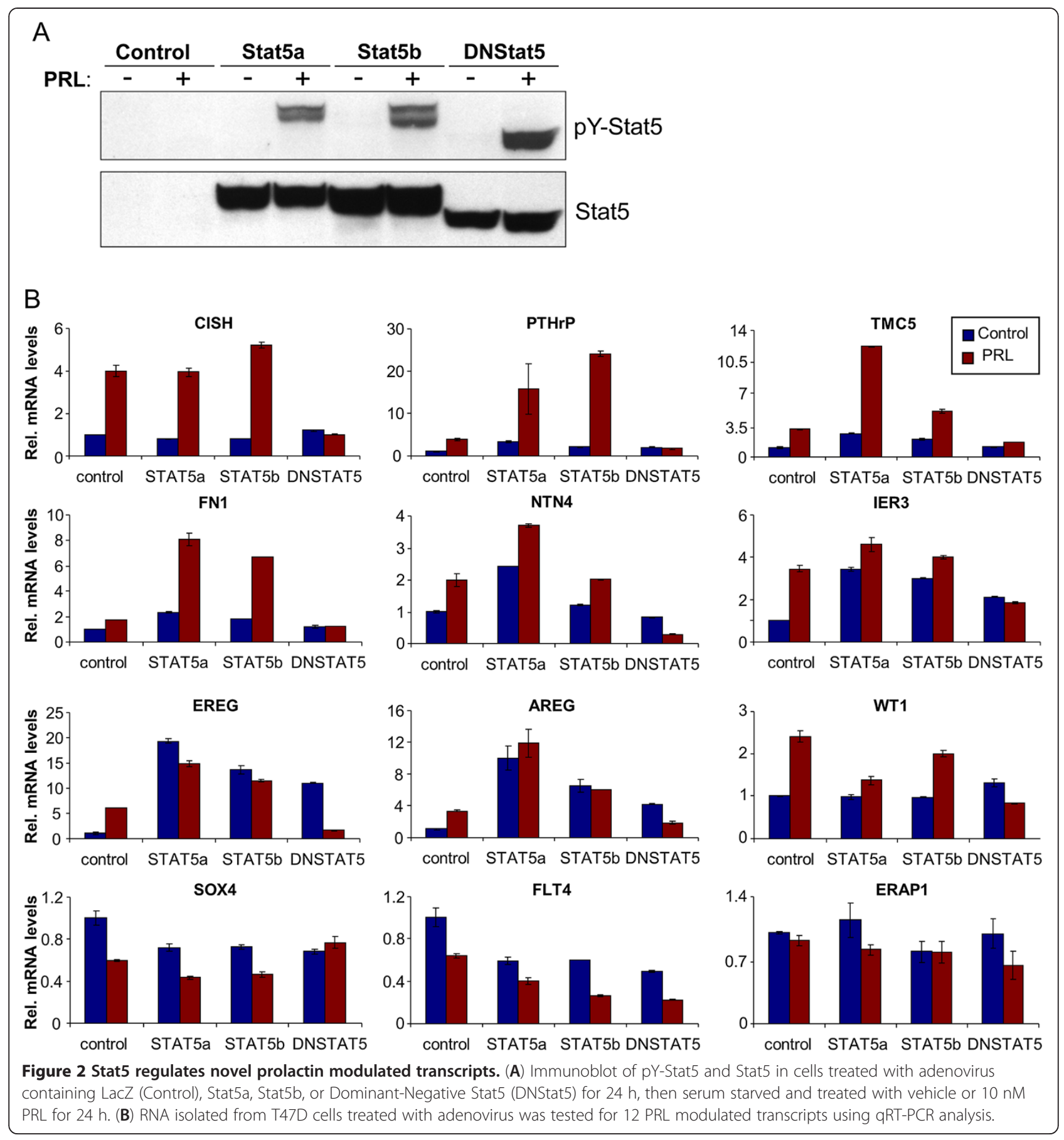

regulation of Jak1 mRNA but not Jak2 mRNA (Figure 3). Conversely, Jak2 shRNA effectively suppressed Jak2 mRNA but not Jak1 mRNA (Figure 3). All nine PRL-upregulated transcripts showed complete dependence on Jak2 (Figure 3). Importantly, all nine PRL-induced transcripts were also partially suppressed by Jak1 knockdown, consistent with a significant role for Jak1 recruitment by PRL in breast cancer cells to maximize downstream signals. Among the three down-regulated transcripts, BCL6 down-regulation by PRL was dependent on Jak2 but not on Jak1, whereas downregulation of FLT4 and SOX4 by PRL was not significant under these experimental conditions, possibly due to cell stress during lentiviral infection (Figure 3). Collectively, these data are consistent with a general model in which Jak2 is critical for PRL receptor signaling and Jak1 recruitment is needed for maximal signal. 


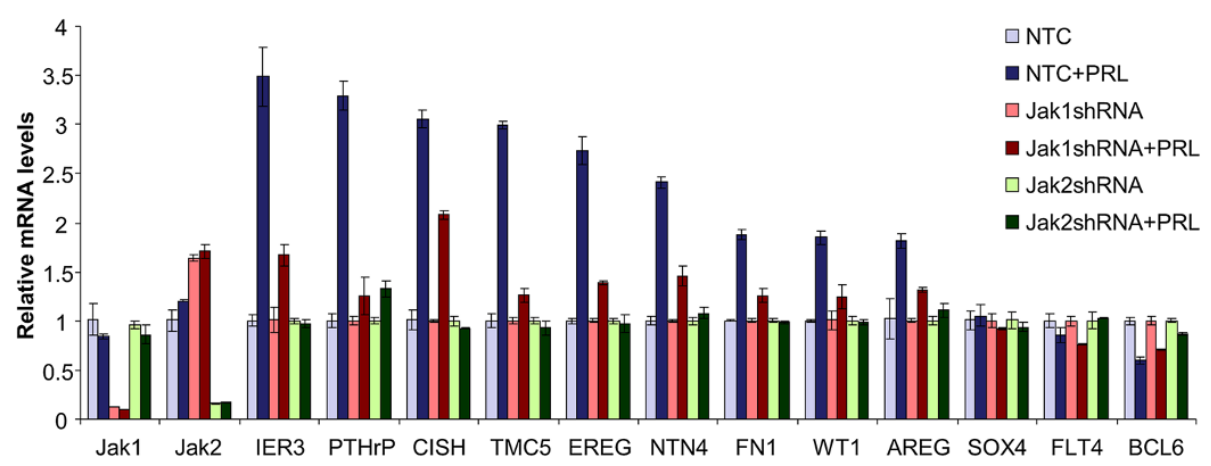

Figure 3 Jak2 and Jak1 are critical for PRL transcript regulation in T47D breast cancer cells. T47D cells were treated with lentivirus containing NTC, Jak1 shRNA, or Jak2 shRNA overnight. Then, cells were placed in serum starvation media for $24 \mathrm{~h}$ and then treated with vehicle or $10 \mathrm{nM}$ PRL for another $24 \mathrm{~h}$ before RNA isolation and $\mathrm{qRT}$-PCR analysis of the $12 \mathrm{PRL}$ regulated transcripts.

\section{Synergistic enhancement by E2 of PRL-induced proliferation and select PRL-modulated genes}

Previous studies have indicated that PRL may enhance E2-induced proliferation as well as additively or synergistically increase transcription of certain PRL or E2 target genes [9-11]. To verify that the PRL-E2 interaction occurred in T47D cells under our culture conditions, we treated T47D cells with varying doses of PRL $(0,1,10$, 20, 37, and $100 \mathrm{nM})$ while keeping E2 constant (1 nM), and determined cell number after $72 \mathrm{~h}$. PRL concentrations as low as $10 \mathrm{nM}$ in the presence of E2 were associated with an increase in cell number compared to E2 alone, and this effect was maintained at higher PRL concentrations (Figure 4A). Next, we maintained constant PRL concentration $(20 \mathrm{nM})$ while varying the E2 dose (0.001, 0.01, 0.1, 1, $10 \mathrm{nM})$, and counted cell numbers after $72 \mathrm{~h}$. At every concentration of E2, we observed a PRL-induced increase in cell number (Figure 4B). We also determined the effect of PRL on E2-driven growth in soft agar and measured colony size after 2 weeks. While PRL alone had limited effect on colony size, E2 increased colony size dramatically, and PRL further increased E2-driven colony size (Figure 4C). Representative images of the colonies in soft agar are displayed in Figure 4D. These data established under our culture conditions that PRL positively interacts with E2 to induce proliferation of luminal T47D breast cancer cells.

To determine whether the PRL-modulated transcript panel was affected by co-treatment with E2, we treated T47D cells with vehicle, PRL, E2, or PRL + E2 for $24 \mathrm{~h}$ and performed qRT-PCR analysis of the 12 transcripts. Seven out of the nine upregulated transcripts displayed further induction with E2 present (NTN4 and TMC5 had no further induction) (Figure 4E). None of the three PRLdownregulated genes displayed further downregulation in the presence of E2 (Figure 4E). This data indicates that E2 is selectively modulating some but not all PRL-Stat 5 regulated transcripts, and these specific transcripts may be playing a role in PRL's ability to increase E2-driven breast cancer cell proliferation.

\section{PTHrP protein levels correlate with levels of pYStat5 in human breast cancer tissues}

To begin to assess the clinical relevance of the newly identified PRL-modulated transcripts, we selected the gene product most strongly upregulated by PRL in the in vivo xenotransplant tumors, PTHrP, for protein expression analysis in clinical breast cancer specimens. We hypothesized that cellular PTHrP protein levels would be positively correlated with levels of nuclear localized and tyrosine phosphorylated Stat5 (Nuc-pYStat5). NucpYStat5 is an indirect measure of PRL receptor activation in breast epithelia, and we documented evidence of Stat5-dependence of PRL-upregulation of PTHrP in T47D cells. Levels of cellular PTHrP and Nuc-pYStat5 were analyzed using fluorescence-based quantitative immunohistochemistry on a breast cancer progression array containing 40 normal and 140 malignant breast tissues. Representative images of PTHrP and pY-Stat5 staining are shown in Figure 5A, where Case 1 has high PTHrP and Nuc-pYStat5 levels, while Case 2 has low PTHrP and Nuc-pYStat5 levels. Evaluable levels of cellular PTHrP and Nuc-pYStat5 were obtained in 92 breast cancer specimens and in support of our hypothesis, a statistically significant positive correlation was detected $(\mathrm{r}=0.51, \mathrm{P}<0.001)$ (Figure 5B).

\section{Gene ontology (GO) terms are enriched in differentiation markers}

Analysis of GO biological process terms using the 75 PRL-upregulated transcripts identified in this study revealed 24 GO terms that had a false discovery rate (FDR) below 25\% (Table 4). Many of the pathways that were identified were homeostasis-related, correlating with the ability of the PRL-Stat5 pathway to maintain cellular differentiation, consistent with established pro- 

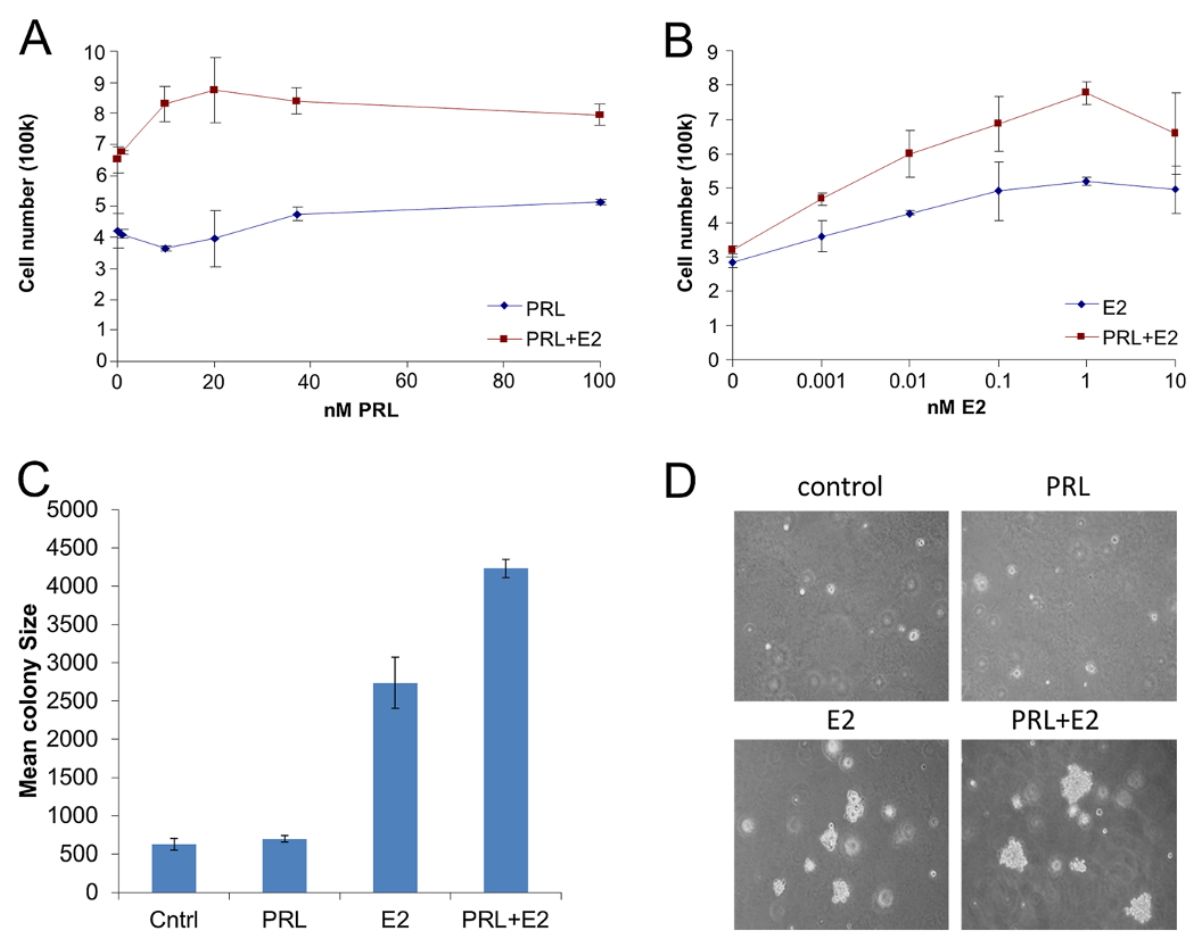

D
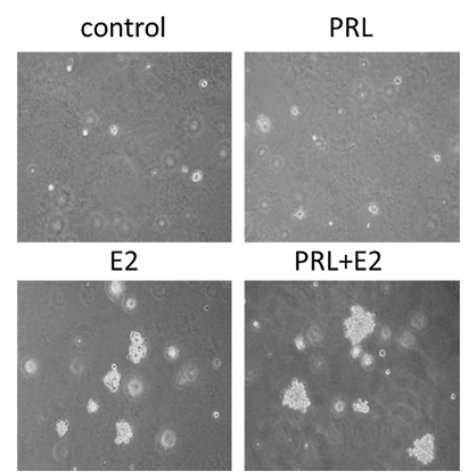

E

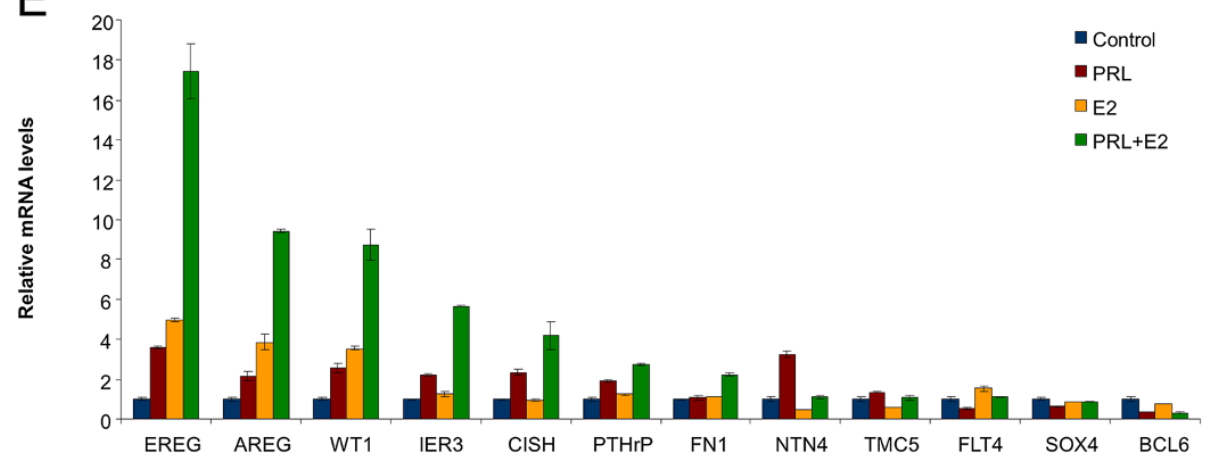

Figure 4 Enhancement by E2 of PRL-induced proliferation and select PRL modulated transcripts. (A) T47D cells were treated with varying doses of PRL $(0,1,10,20,37$, and $100 \mathrm{nM})$ in the presence of constant E2 (1 nM) for $72 \mathrm{~h}$. Bars represent triplicates of each condition that were counted and averaged. (B) T47D cells were treated with varying doses of E2 $(0.001,0.01,0.1,1,10 \mathrm{nM}$ ) in the presence of constant PRL (20 nM) for $72 \mathrm{~h}$. Bars represent triplicates of each condition that were counted and averaged. (C) T47D cells were treated with vehicle, $20 \mathrm{nM}$ PRL, $1 \mathrm{nM}$ E2, or $20 \mathrm{nM} \mathrm{PRL}+1 \mathrm{nM}$ E2 for 2 weeks. Images from four independent wells were analyzed for colony size through ImageJ. (D) Representative images of T47D cells grown on soft agar and treated with vehicle, PRL, E2, or PRL + E2 for 2 weeks. (E) T47D cells were treated with PRL, E2, or $\mathrm{PRL}+\mathrm{E} 2$ for $24 \mathrm{~h}$. RNA was isolated and GRT-PCR analysis was performed on the $12 \mathrm{PRL}$ modulated transcripts.

differentiation effects of PRL on normal and malignant luminal breast epithelial cells. In addition, proliferationregulation and negative regulation of apoptosis were also identified, which is consistent with the reported role of PRL contributing to breast cancer initiation and growth.

\section{Prolactin-upregulated gene signature is associated with prolonged time to relapse and metastasis}

We then determined whether the PRL-upregulated gene signature was associated with clinical outcome, using an available 49 of 75 PRL-upregulated genes (Table 5) in a cohort of 936 primary invasive breast cancer patients. We divided the patients into three groups based on their degree of expression of the PRL-gene signature (upper quartile, interquartile range, and lower quartile). The patients in the upper quartile had significantly prolonged time to metastasis compared to patients associated with the lower quartile (Figure 6A). In addition, patients that were in the upper quartile also had significantly prolonged disease-free survival than patients in the lower quartile (Figure 6B). 




B

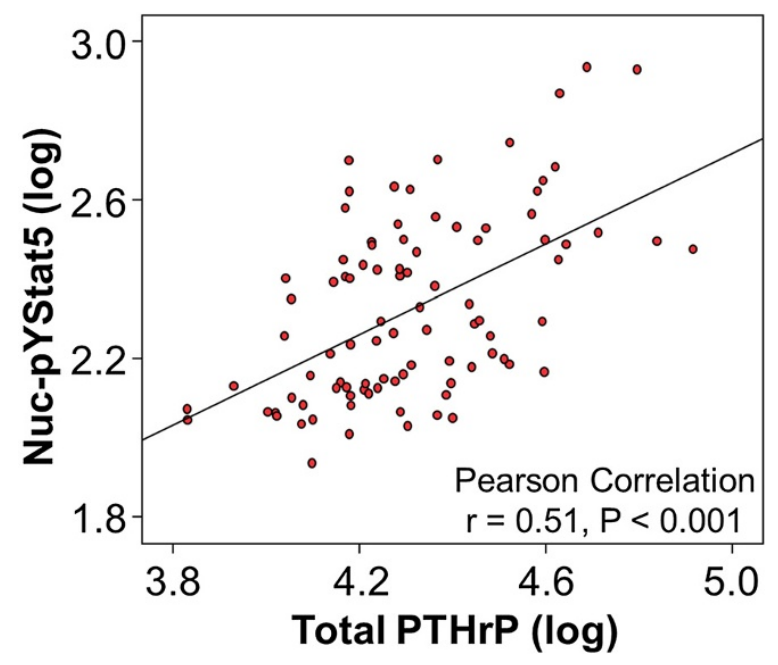

Figure 5 PTHrP protein levels correlate with levels of nuc-pYStat5 in human breast cancer tissues. (A) Representative immunofluroescent images of two cases of breast cancer stained for pY-Stat5 (Red), PTHrP (Red), cytokeratin (Green), and DNA (Blue) using immunohistochemistry. (B) Scatter plot and Pearson correlation analysis between nuc-pYStat5 and cellular PTHrP protein levels on 92 breast cancer specimens.

\section{Discussion}

The present study reports a novel panel of PRLmodulated transcripts based on analysis of human breast cancer xenograft tumors in vivo. We identified 75 upregulated and 55 down-regulated transcripts that were significantly modulated based on at least a 1.6-fold change with a P-value less than 0.05 . From this panel of 130 PRL-modulated transcripts, a subset of 18 transcripts with established breast cancer-relevance was selected for further analysis and validation. Validation by qRT-PCR documented significant modulation of 12 of
18 transcripts in vitro. We further documented that the majority of in vitro-modulated transcripts were Stat5and Jak2-dependent, and showed that Jak1 was required for maximal PRL-modulation. Consistent with PRLenhancement of E2-driven proliferation of breast cancer cells, select PRL-modulated transcripts displayed positive co-regulation by E2, including the growth factors EREG and AREG. These molecular results are summarized in Table 6. Furthermore, quantitative immunofluorescence analyses of clinical breast cancer specimens from a cohort of 92 patients documented a significant positive correlation between tumor levels of PTHrP protein, one of the PRL-stimulated transcripts, and nuclear localized and tyrosine phosphorylated Stat5, a marker of PRL signaling. Gene ontology analysis revealed that prolactinupregulated genes were associated most frequently with terms involved in homeostasis and differentiation. Finally, a gene signature generated with PRL-upregulated genes was associated with prolonged relapse-free survival as well as metastasis-free survival in a cohort of breast cancer patients. Collectively, the validation studies support the value of the transcript data and are expected to facilitate better understanding of PRL action in breast cancer.

PRL activates both Stat5a and Stat5b, which have 92\% amino acid similarity [35], but are encoded by different genes and may mediate overlapping and distinct effects in breast cancer cells [17,33,36-38]. In the present study, which focused on PRL-modulated transcripts in the T47D breast cancer model, experimental overexpression of Stat5a or Stat $5 b$ enhanced to a comparable extent PRLmodulation of most transcripts tested. However, TMC5, NTN4, and AREG displayed greater degree of enhanced PRL-modulation when Stat5a was overexpressed rather than Stat5b, supporting the notion that certain genes are more responsive to Stat5a than Stat5b. PRL-modulation of all examined transcripts with the exception of PRLinduced down-regulation of FLT4 mRNA was disrupted by overexpression of a C-terminally truncated Stat5 variant that acts as a dominant-negative molecule for both Stat5a and Stat5b. This exception is consistent with previous reports that repression of certain Stat 5 target genes is unaffected by alterations in the Stat 5 transactivation domain $[33,39]$. We have recently reported that Stat5a but not Stat5b expression was lost during progression of human breast cancer, and in cultured MCF-7 cells there was only a limited overlap in transcripts modulated by the two PRL-activated transcription factors [17]. It is possible that in T47D cells the higher basal levels of Stat5a and especially Stat5b make it more difficult to ascertain differences between the two transcription factors in overexpression studies. Future transcript analyses will focus on further characterizing the differences in gene regulation between Stat5a and Stat5b in human breast cancer. 
Table 4 Gene Ontology (GO) analysis of PRL upregulated genes with false discovery rate (FDR) $<25$

\begin{tabular}{|c|c|c|c|}
\hline GO Term & Description & $P$ value & FDR \\
\hline GO:0030005 & cellular di-, tri-valent inorganic cation homeostasis & 0.002 & 2.452 \\
\hline GO:0042592 & homeostatic process & 0.002 & 2.848 \\
\hline GO:0055066 & di-, tri-valent inorganic cation homeostasis & 0.002 & 3.079 \\
\hline GO:0030003 & cellular cation homeostasis & 0.003 & 4.015 \\
\hline GO:0055080 & cation homeostasis & 0.004 & 6.550 \\
\hline GO:0006879 & cellular iron ion homeostasis & 0.006 & 8.210 \\
\hline GO:0043123 & positive regulation of I-kappaB kinase/NF-kappaB cascade & 0.006 & 9.136 \\
\hline GO:0060249 & anatomical structure homeostasis & 0.008 & 10.970 \\
\hline GO:0055072 & iron ion homeostasis & 0.008 & 11.045 \\
\hline GO:0019725 & cellular homeostasis & 0.008 & 11.791 \\
\hline GO:0043122 & regulation of I-kappaB kinase/NF-kappaB cascade & 0.008 & 11.809 \\
\hline GO:0048514 & blood vessel morphogenesis & 0.009 & 12.950 \\
\hline GO:0051052 & regulation of DNA metabolic process & 0.010 & 13.580 \\
\hline GO:0042127 & regulation of cell proliferation & 0.010 & 13.992 \\
\hline GO:0043066 & negative regulation of apoptosis & 0.011 & 15.532 \\
\hline GO:0043069 & negative regulation of programmed cell death & 0.012 & 16.371 \\
\hline GO:0060548 & negative regulation of cell death & 0.012 & 16.542 \\
\hline GO:0048878 & chemical homeostasis & 0.013 & 17.642 \\
\hline GO:0006873 & cellular ion homeostasis & 0.014 & 18.854 \\
\hline GO:0055082 & cellular chemical homeostasis & 0.014 & 19.975 \\
\hline GO:0001568 & blood vessel development & 0.015 & 20.556 \\
\hline GO:0010627 & regulation of protein kinase cascade & 0.015 & 20.807 \\
\hline GO:0001944 & vasculature development & 0.016 & 22.079 \\
\hline
\end{tabular}

Jak1 was reported to be activated by PRL signaling in human breast cancer lines and cooperate with Jak2 to enhance signaling pathways downstream of PRL receptors, including Stat5, Stat3 and Erk activation [31]. The present study validates the notion that Jak1-coactivation enhances PRL-Jak2 signaling by demonstrating that maximal PRLmodulation of target transcripts required PRL-induced co-activation of Jak1. Future studies to identify the mechanism of activation of Jak1 by PRL receptors in breast cancer and the effect of Jak1-activation on PRL-modulated biology of breast cancer are now warranted.

Furthermore, whereas PRL alone exerted limited proliferative effect on T47D breast cancer cells in vitro, PRL enhanced E2-driven cell proliferation both on plastic and soft agar. PRL positively interacted with E2 to further elevate several transcripts encoding growth and progression factors for breast cancer, including AREG, EREG, PTHrP and WT1. Considering the established role for AREG as a paracrine mediator of E2-induced proliferation of luminal breast epithelial cells during $\mathrm{pu}-$ bertal growth [40], AREG may be directly involved in PRL stimulation of E2-driven growth of human breast cancer. A recent study has implicated PRL receptors in the maintenance of ER expression and responsiveness of breast cancer cells to estrogen [28], which is consistent with our findings which demonstrate significant crosstalk between the two pathways. Since Stat 5 has been associated with response to anti-estrogen therapy in clinical breast cancer specimens [16,17], this synergistic stimulation of proliferation with estrogen may be a mechanism behind increased responsiveness to antiestrogen treatments. In addition, PRL biological action may vary depending on the hormonal environment, especially given our recent observation that PRL effectively counteracts progestin-induction of the tumor-initiating CK5-positive cell population [21].

We identified PRL-suppression of BCL6 transcript and protein based on this global transcript analysis of T47D xenotransplants tumors, and we reported a negative correlation between levels of BCL6 protein and Nuc-pYStat5 in clinical breast cancer specimens [33]. The fact that the protein products of two of the PRLmodulated genes identified in this global transcript profiling, PTHrP and BCL6, both correlated with NucpYStat5 in human clinical breast cancer specimens indicates that transcripts identified in the present study are relevant in clinical specimens and may become useful human breast tumor markers of PRL activation. 
Table 5 PRL-upregulated genes used to generate PRL gene signature

\begin{tabular}{|c|c|c|c|}
\hline $\begin{array}{l}\text { Gene } \\
\text { Symbol }\end{array}$ & $\begin{array}{c}\text { Correlation } \\
\text { with signature } \\
\text { average }\end{array}$ & $\begin{array}{l}\text { Gene } \\
\text { symbol }\end{array}$ & $\begin{array}{c}\text { Correlation } \\
\text { with signature } \\
\text { average }\end{array}$ \\
\hline AREG & 0.6 & TNIK & 0.25 \\
\hline DUSP4 & 0.51 & PPM1H & 0.17 \\
\hline PTHLH & 0.46 & PAR5 & 0.15 \\
\hline EREG & 0.45 & INVS & 0.14 \\
\hline SCAMP1 & 0.43 & CSDA & 0.13 \\
\hline TMC5 & 0.42 & MYC & 0.12 \\
\hline GADD45A & 0.42 & WT1 & 0.09 \\
\hline CHSY1 & 0.41 & $\mathrm{CISH}$ & 0.08 \\
\hline TFF1 & 0.4 & $\mathrm{CP}$ & 0.07 \\
\hline FGD6 & 0.39 & RGS16 & 0.07 \\
\hline $\mathrm{BACH} 1$ & 0.38 & NF2 & 0.07 \\
\hline AHCYL1 & 0.37 & FGFR2 & 0.04 \\
\hline EGLN3 & 0.34 & RNGTT & 0.03 \\
\hline AMIGO2 & 0.33 & FN1 & 0.02 \\
\hline TNFSF10 & 0.33 & $\mathrm{ITCH}$ & -0.01 \\
\hline IER3 & 0.33 & LARGE & -0.11 \\
\hline ANKRD6 & 0.32 & PSMB2 & -0.12 \\
\hline ACOX2 & 0.31 & SECTM1 & -0.15 \\
\hline SLC30A1 & 0.31 & GLDC & -0.2 \\
\hline ERAP1 & 0.31 & AIPL1 & -0.21 \\
\hline RNF38 & 0.3 & TGM2 & -0.22 \\
\hline ZFP36L2 & 0.3 & DDX54 & -0.23 \\
\hline CCR6 & 0.28 & MFI2 & -0.27 \\
\hline HEY2 & 0.25 & ARHGDIG & -0.27 \\
\hline TK2 & 0.25 & & \\
\hline
\end{tabular}

Supporting the validity of the identified panel of PRLmodulated transcripts in T47D cells in vivo, 12 out of the 57 transcripts identified as PRL-modulated transcripts in a recent in vitro transcript profiling study of T47D cells overlapped with our panel (AREG, WT1, PTHrP, IER3, TMC5, CISH, BCL6, DUSP4, TNIK, EGLN3, FBXO32, and AKAP9) [9]. Only WT1 and IER3 transcripts were tested and confirmed by qRT-PCR in the previous report. In addition, select transcripts identified in the previous study such as WT1 and IER3 demonstrated co-regulation by E2 [9], consistent with the findings of the present study. In vitro transcript profiling for PRL-modulated transcripts in another ER-positive human breast cancer cell line, MCF7, using Stat5 overexpression to enhance PRL effects, yielded 300 candidate PRL-modulated transcripts among which 12 overlapped with the panel identified in the present study of T47D cells (CISH, EGLN3, KCNK6, PTHrP, FN1, CHSY1, BCL6, DUSP4, IGFBP5, TNIK, ABCC4, and MYC) [17].
The limited overlap between our current study of T47D cells and two recent studies of MCF-7 cells in vitro may be due to lower expression levels of Stat 5 in MCF-7 cells, making it necessary to overexpress Stat5 [17] or PRL receptor [28]. While previous studies were performed in vitro and did not broadly validate identified candidate PRL-modulated transcripts by qRT-PCR, the present study also provides novel data by demonstrating PRL-regulation of transcripts in vivo and through Jak-Stat5 dependent mechanisms.

The established breast cancer relevance for AREG, WT1, and IER3 is discussed in a previous transcript profiling study [9]. NTN4 is a transmembrane protein whose expression levels positively correlates with better prognosis in breast cancer [41]. TMC5 is a transmembrane channel that was overexpressed in PIK3CAmutated breast cancer [42]. FN1 is a protein present in the extracellular matrix that is a candidate serum biomarker for detecting breast cancer [43], and disrupting the interaction between FN1 and integrins in breast cancer cells led to increased apoptosis and response to radiation [44]. EREG is a ligand for EGFR and Her4, and was reported to be part of a set of four genes that promote breast cancer intravasation and metastasis to the lung [45]. PTHrP is a secreted protein critical for mammary gland development [46], and extensive research has been performed on its role in mediating breast cancer metastasis to bone [47-49]. SOX4 is a transcription factor regulated by progesterone in breast cancer cells [50], and was identified as an oncogene in prostate cancer [51]. FLT4 is a member of the VEGF receptor family, and expression in vessels surrounding breast tumors was correlated to lymph node positivity and poor clinical outcome [52]. These genes clearly demonstrate the complexity of PRL effects, since PRL has the ability to suppress oncogenes (SOX4, FLT4, BCL6) and upregulate favorable prognostic markers (NTN4), while also upregulating genes involved in breast cancer growth and progression (AREG, WT1, IER3, EREG, TMC5, FN1, PTHrP). These observations are consistent with the many reported conflicting and likely context-dependent effects of PRL in breast cancer.

Furthermore, gene ontology (GO) analysis based on PRL-upregulated genes demonstrated a concentration in homeostasis pathways, consistent with the known prodifferentiation role of PRL in breast cancer. However, other terms such as cell proliferation and anti-apoptosis were also enriched, most likely reflecting the duality of PRL action. Consistent with the enrichment of differentiation terms in the GO analysis, a PRL gene signature generated on PRL-upregulated genes was associated with prolonged time to relapse and metastasis-free survival. These associations are consistent with the multiple reports that Stat5 is associated with favorable prognosis in breast cancer patients [14-16]. In addition, we have 

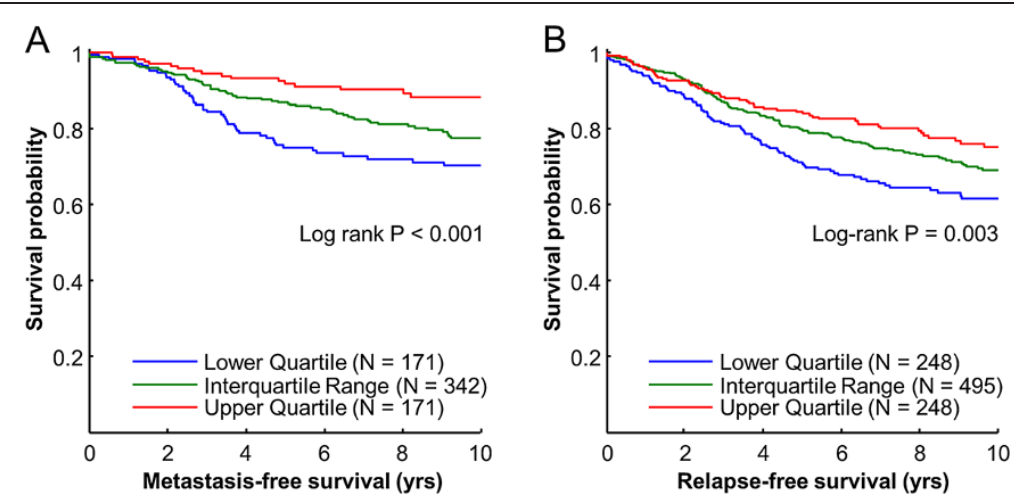

Figure 6 PRL upregulated gene signature is associated with metastasis-free and relapse-free survival. (A) Patients with high levels of a genes signature of PRL-upregulated had reduced risk of developing metastasis compared to patients with low levels of the PRL-upregulated gene signature. (B) Patients with high levels of the PRL-induced gene signature had prolonged relapse-free survival compared to patients with low levels of the PRL gene signature.

recently reported that prolactin can suppress a therapyresistant, tumor-initiating CK5-positive population induced by progestin [21]. Our results are consistent with a role of PRL in reducing the tumor-initiating CK5positive cell population, which is implicated in breast cancer metastasis and relapse.

\section{Conclusions}

The present study is the first to report a panel of PRLmodulated transcripts based on global transcript profiling of human breast cancer xenotransplant tumors in vivo. Some but not all transcripts were also modulated by PRL in vitro. PRL-enhancement of E2-driven proliferation of T47D cells in vitro may be mediated by observed coregulation by PRL and E2 of growth-promoting genes including AREG, EREG, WT1 and PTHrP. PRL-modulated transcripts reported in this study are expected to facilitate deciphering of the mechanisms underlying the pleotropic effects of PRL on breast cancer. PRL-upregulated genes were frequently associated with differentiation pathways. Finally, select transcripts or their protein complement identified in this study also may be useful as breast cancer tumor marker signatures of PRL activation, which is highly relevant considering our report that PRL gene

Table 6 Summary of transcript regulation

\begin{tabular}{|c|c|c|c|c|c|c|c|}
\hline Gene & $\begin{array}{l}\text { Fold Change } \\
\text { (microarray) }\end{array}$ & $\begin{array}{c}\text { in vivo } \\
\text { Regulation }\end{array}$ & $\begin{array}{c}\text { in vitro } \\
\text { Regulation }\end{array}$ & $\begin{array}{c}\text { Stat5 } \\
\text { Regulation }\end{array}$ & $\begin{array}{c}\text { Jak2 } \\
\text { Regulation }\end{array}$ & $\begin{array}{c}\text { Jak1 } \\
\text { Regulation }\end{array}$ & $\begin{array}{c}\text { E2 } \\
\text { Regulation }\end{array}$ \\
\hline PTHrP & 11.9 & Y & Y & Y & Y & Y & Y \\
\hline CCR6 & 4.9 & Y & $N$ & Y & Y & Y & Y \\
\hline IER3 & 3.4 & Y & Y & Y & Y & Y & Y \\
\hline AMIGO2 & 3.3 & Y & $N$ & NA & NA & NA & NA \\
\hline EREG & 3.2 & Y & Y & Y & Y & Y & Y \\
\hline ERAP1 & 3.0 & N & $N$ & NA & NA & NA & NA \\
\hline DUSP4 & 2.7 & Y & $N$ & NA & NA & NA & NA \\
\hline $\mathrm{CISH}$ & 2.6 & Y & Y & Y & Y & Y & Y \\
\hline TMC5 & 2.5 & Y & Y & Y & Y & Y & N \\
\hline AREG & 2.4 & Y & Y & Y & Y & Y & Y \\
\hline FN1 & 2.3 & Y & Y & Y & Y & Y & Y \\
\hline NTN4 & 2.2 & Y & Y & Y & Y & Y & N \\
\hline WT1 & 2.1 & Y & Y & Y & Y & Y & Y \\
\hline GADD45A & 1.8 & N & $N$ & NA & NA & NA & NA \\
\hline FGFR2 & 1.8 & N & $N$ & NA & NA & NA & NA \\
\hline BCL6 & -2.8 & Y & Y & Y & Y & $\mathrm{N}$ & N \\
\hline SOX4 & -2.0 & Y & Y & Y & NA & NA & $N$ \\
\hline FLT4 & -2.0 & Y & Y & Y & NA & NA & N \\
\hline
\end{tabular}


signature is associated with relapse-free survival and metastasis-free survival, and the already documented association of Stat 5 with breast cancer prognosis and hormone therapy responsiveness.

\section{Materials and methods}

Tissue culture

T47D cells were cultured in RPMI (Cellgro) containing $10 \%$ fetal bovine serum (FBS) and $1 \mathrm{mM}$ sodium pyruvate (Cellgro). For PRL induction, confluent T47D cells were put in serum starvation media (RPMI without FBS) for $24 \mathrm{~h}$, and then stimulated with either PBS vehicle or $10 \mathrm{nM}$ of recombinant human prolactin (AFP795, provided by Dr. A.F. Parlow at National Hormone and Pituitary Program) for $24 \mathrm{~h}$. $24 \mathrm{~h}$ prior to experiments involving $\beta$-Estradiol (Sigma), media was changed to RPMI containing 5\% Charcoal Stripped Serum (Thermo Scientific) and $1 \mathrm{mM}$ sodium pyruvate.

\section{Xenotransplants}

Nude mice $(\mathrm{N}=20)$ were implanted with $17 \beta$-estradiol pellets $(0.72 \mathrm{mg}$; Innovative Research of America) and injected subcutaneously with T47D cells $\left(5 \times 10^{6}\right)$ suspended in Matrigel into two dorsolateral sites. Tumors were allowed to grow for 6 weeks and subsequently were injected subcutaneously with either saline $(\mathrm{N}=10)$ or $5 \mu \mathrm{g} / \mathrm{g}$ body mass of human prolactin $(\mathrm{N}=10)$ every $12 \mathrm{~h}$ for $48 \mathrm{~h}$ total. Tumors were harvested and processed for immunohistochemistry and qRT-PCR. All research involving mice were approved by Thomas Jefferson IACUC (protocol $789 \mathrm{C}$ to H.R.) in accordance with international guidelines for ethical treatment of animals.

\section{Microarray}

RNA was pooled into 3 groups from PRL injected mice and 3 groups from saline injected mice, with each group containing RNA from 3-4 mice. Microarray analysis was performed for each group using the Affymetrix HGU133 GeneChip Set (Expression Analysis). Two group comparison analyses were conducted on normalized expression values that were individually transformed using base 2 logarithms. On the log-transformed scale, the mean is calculated for every gene within each group and a two-sample, two-sided t-test is conducted to test the equality of those means. The P-value indicates the significance level of this test.

\section{Quantitative reverse transcription polymerase chain reaction}

Quantitative RT-PCR assays were performed with RNA samples isolated from T47D cells using RNeasy kit (Qiagen). cDNA was generated using Iscript (Bio-Rad) according to the manufacturer's protocol. cDNAs were subjected to qPCR using corresponding primers (Table 7).

Table 7 Primer sequences

\begin{tabular}{|c|c|c|}
\hline Gene & Forward primer & Reverse primer \\
\hline PTHrP & GTTCCTGGTGAGCTACGCG & CTTGGATGGACTTCCCCTTG \\
\hline CCR6 & TGCTACCGCTGCCTGTGAGC & AAAATAATCTTCACTGGAGTCG \\
\hline IER3 & CGTCCTCGAGCCCTITAATCT & AGGTCCAGAGCGTAGTCCGA \\
\hline AMIGO2 & CCGGTGTCTITTCCACCG & GAGCCCACGAGGCTCC \\
\hline EREG & GCTCTGCCTGGGTTTCCATC & CCACACGTGGATTGTCTTCTGTC \\
\hline ERAP1 & GCCATTCTAGCTGCAGTGGG & CAACTGTGTACGGGAGCCC \\
\hline DUSP4 & TACAAGTGCATCCCAGTGGA & CCCGTTTCTTCATCATCAGG \\
\hline $\mathrm{CISH}$ & CTGCTGTGCATAGCCAAGAC & GTGCCTTCTGGCATCTTCTG \\
\hline TMC5 & TATCCTTCAGCTCAATTGCTG & AGAGGACGCTGGTTCCAAAC \\
\hline AREG & GGTGGTGCTGTCGCTCTTG & TCAGCACTGTGGTCCCCAG \\
\hline FN1 & TTCTACTCCTGCACACAGAAG & CCCTCAGAAGTGCAATCAGTG \\
\hline NTN4 & CATGGTGGGATACTGGGGC & TCAGGAACTTCATGATACCAGTC \\
\hline WT1 & GAGAGCCAGCCCGCTATTC & CATGGGATCCTCATGCTTG \\
\hline GADD45A & TCAGCGCACGATCACTGTC & CCAGCAGGCACAACACCAC \\
\hline FGFR2 & СTCACTCTCACAACCAATGAGG & AGGAAGGCATGGTTCGTAAG \\
\hline $\mathrm{BCL} 6$ & CTGCAGATGGAGCATGTTGT & TCTTCACGAGGAGGCTTGAT \\
\hline SOX4 & GTGAGCGAGATGATCTCGGG & CAGGTTGGAGATGCTGGACTC \\
\hline FLT4 & CAGGATGAAGACATITGAGG & AAGAAAATGCTGACGTAT \\
\hline GAPDH & AATCCATCACCATCTTCCA & TGGACTCCACGACGTACTCA \\
\hline ERAP1 & GCCATTCTAGCTGCAGTGGG & CAACTGTGTACGGGAGCCC \\
\hline
\end{tabular}




\section{Immunohistochemistry}

Immunohistochemistry and AQUA analyses were performed on a tissue array generated by cutting-edge matrixassembly containing 100 deidentified primary invasive breast carcinoma specimens in a cohort described previously [33]. Immunohistochemistry was performed as described previously [33] using pY-Stat5 (Epitomics, 1:200), PTHrP (Santa Cruz, 1:200), and cytokeratin (DAKO, 1:100). AQUA analysis was performed using AQUA/ PM2000 (HistoRx) as described previously [33].

\section{Adenoviral and lentiviral production and infection}

Lentiviral particle production was performed as described previously [33]. shRNA lentiviral vectors (Open Biosystems, Lafayette, CO, USA) were obtained for scrambled control (SC002), and Jak1 (TRCN0000003102), and Jak2 (TRCN0000003180). The cells were infected with lentivirus overnight and allowed to grow for $48 \mathrm{~h}$ before hormone induction for an additional 24 h. LacZ, Stat5a, Stat5b, and Dominant-negative-Stat5 (DN-Stat5) adenoviruses were prepared using double cesium chloride centrifugation [53] and used for gene delivery into T47D cells $\left(1.5 \times 10^{6} /\right.$ well in 6 well dish; multiplicity of infection $\left.=5\right)$. $24 \mathrm{~h}$ after infection, cells were incubated with hormones for another $24 \mathrm{~h}$ and subsequently harvested for immunoblot analysis.

\section{Cell proliferation and soft agar assays}

T47D cells were treated with vehicle, PRL, or $17 \beta$-Estradiol (E2) (Sigma) for $72 \mathrm{~h}$. Triplicates of each condition were plated and counted using the Countess Automated Cell Counter (Invitrogen). For the soft agar assay, T47D cells suspended in $0.3 \%$ agarose were plated on top of $0.6 \%$ agarose. T47D cells were treated with media containing either vehicle, PRL (20 nM), E2 (10 nM), or PRL + E2 for 2 weeks, with fresh media and hormones added every 3 days. Each condition was done in quadruplicate. Images were taken from each well at 2 weeks and were analyzed for colony size using ImageJ.

\section{Immunoblotting}

T47D cells were lysed as described previously [54]. Proteins were resolved by SDS-PAGE and immunoblotted with antibodies to phospho-Stat5 (AX1, Advantex), and total Stat5 (BD \#610192), followed by secondary antibodies Alexa Fluor 680-conjugated goat anti-mouse IgG (Invitrogen) or IRDye $800 \mathrm{CW}$-conjugated goat antirabbit IgG (Licor, Lincoln, NE, USA) depending on primary antibodies. Immunoblots were scanned using the Odyssey Infrared Imaging System (Licor).

\section{Gene ontology analysis and survival analyses}

The PRL-regulated genes identified using mRNA expression microarrays were analyzed for enrichment of Gene
Ontology Biological Process terms using the Database for Annotation, Visualization and Integrated Discovery (DAVID ) v6.7 [55,56]. A previously described collection of mRNA microarray datasets compiled from public repositories [57] was used to evaluate the set of PRLinduced transcripts in the context of clinical outcome. Transcription levels for PRL-upregulated genes were averaged into an expression signature and used to divide samples into the lower quartile, interquartile range, and upper quartile. Relapse-free and metastasis-free survival differences in these groups were evaluated for significance using the log rank test.

\section{Competing interests}

The authors declared that they have no competing interest.

\section{Authors' contributions}

TS performed all qRT-PCR experiments, knockdown experiments, proliferation assays, RNA isolation for most of the in vitro experiments, analysis of experimental results, creation of the figures, and drafted the manuscript. THT provided insight into study design, analysis of experimental results, and isolated RNA for the adenovirus experiments. ARP performed the adenovirus and soft agar experiments. CL performed immunohistochemistry and AQUA analysis. AE performed $\mathrm{GO}$ analysis and survival analyses in public mRNA data sets. JL was responsible for investigation of NTN4 and TMC5 regulation by PRL. LMN performed the T47D xenograft experiment and isolation of RNA from the xenografts. HR provided oversight, guidance and scientific input to the project and finalized the manuscript. All authors read, edited, and approved the final manuscript.

\section{Acknowledgements}

We thank Jessica Davison for editorial assistance with the manuscript. This work was supported by Komen for the Cure Promise Grant KG091116 (H.R., T. S., A.R.P., C.L.), NIH grants CA101841 (H.R.), CA118740 (H.R.), and NCI Support Grant 1P30CA56036 to the Kimmel Cancer Center. The Project is funded, in part, under a Commonwealth University Research Enhancement Program grant with the Pennsylvania Department of Health (H.R.). The Department specifically disclaims responsibility for any analyses, interpretations or conclusions.

\section{Received: 21 February 2013 Accepted: 15 May 2013}

Published: 12 June 2013

\section{References}

1. Rose-Hellekant TA, Arendt LM, Schroeder MD, Gilchrist K, Sandgren EP, Schuler LA: Prolactin induces ERalpha-positive and ERalpha-negative mammary cancer in transgenic mice. Oncogene 2003, 22:4664-4674.

2. Vomachka AJ, Pratt SL, Lockefeer JA, Horseman ND: Prolactin gene-disruption arrests mammary gland development and retards T-antigen-induced tumor growth. Oncogene 2000, 19:1077-1084

3. Tworoger SS, Eliassen AH, Sluss P, Hankinson SE: A prospective study of plasma prolactin concentrations and risk of premenopausal and postmenopausal breast cancer. J Clin Oncol 2007, 25:1482-1488.

4. Tworoger SS, Sluss P, Hankinson SE: Association between plasma prolactin concentrations and risk of breast cancer among predominately premenopausal women. Cancer Res 2006, 66:2476-2482.

5. Reynolds C, Montone KT, Powell CM, Tomaszewski JE, Clevenger CV: Expression of prolactin and its receptor in human breast carcinoma. Endocrinology 1997, 138:5555-5560.

6. Gill S, Peston D, Vonderhaar BK, Shousha S: Expression of prolactin receptors in normal, benign, and malignant breast tissue: an immunohistological study. J Clin Pathol 2001, 54:956-960.

7. Shiu RP: Prolactin receptors in human breast cancer cells in long-term tissue culture. Cancer Res 1979, 39:4381-4386.

8. Schroeder MD, Symowicz J, Schuler LA: PRL modulates cell cycle regulators in mammary tumor epithelial cells. Mol Endocrinol 2002, 16:45-57. 
9. Rasmussen LM, Frederiksen KS, Din N, Galsgaard E, Christensen L, Berchtold MW, Panina S: Prolactin and oestrogen synergistically regulate gene expression and proliferation of breast cancer cells. Endocr Relat Cancer 2010, 17:809-822.

10. Chen Y, Huang K, Chen KE, Walker AM: Prolactin and estradiol utilize distinct mechanisms to increase serine-118 phosphorylation and decrease levels of estrogen receptor alpha in T47D breast cancer cells. Breast Cancer Res Treat 2010, 120:369-377.

11. Gutzman JH, Nikolai SE, Rugowski DE, Watters JJ, Schuler LA: Prolactin and estrogen enhance the activity of activating protein 1 in breast cancer cells: role of extracellularly regulated kinase 1/2-mediated signals to c-fos. Mol Endocrinol 2005, 19:1765-1778.

12. Gouilleux F, Wakao H, Mundt M, Groner B: Prolactin induces phosphorylation of Tyr694 of Stat5 (MGF), a prerequisite for DNA binding and induction of transcription. EMBO J 1994, 13:4361-4369.

13. Liu X, Robinson GW, Gouilleux F, Groner B, Hennighausen L: Cloning and expression of Stat5 and an additional homologue (Stat5b) involved in prolactin signal transduction in mouse mammary tissue. Proc Natl Acad Sci U S A 1995, 92:8831-8835.

14. Nevalainen MT, Xie J, Torhorst J, Bubendorf L, Haas P, Kononen J, Sauter G, Rui $\mathrm{H}$ : Signal transducer and activator of transcription-5 activation and breast cancer prognosis. J Clin Oncol 2004, 22:2053-2060.

15. Yamashita $H$, Nishio M, Ando $Y$, Zhang Z, Hamaguchi M, Mita K, Kobayashi S, Fujii Y, Iwase H: Stat5 expression predicts response to endocrine therapy and improves survival in estrogen receptor-positive breast cancer. Endocr Relat Cancer 2006, 13:885-893.

16. Peck AR, Witkiewicz AK, Liu C, Stringer GA, Klimowicz AC, Pequignot E, Freydin B, Tran $\mathrm{TH}$, Yang N, Rosenberg AL, et al: Loss of nuclear localized and tyrosine phosphorylated Stat5 in breast cancer predicts poor clinical outcome and increased risk of antiestrogen therapy failure. $J$ Clin Oncol 2011, 29:2448-2458.

17. Peck AR, Witkiewicz AK, Liu C, Klimowicz AC, Stringer GA, Pequignot E, Freydin B, Yang N, Ertel A, Tran TH, et al: Low levels of Stat5a protein in breast cancer are associated with tumor progression and unfavorable clinical outcomes. Breast Cancer Res 2012, 14:R130.

18. Sultan AS, Xie J, LeBaron MJ, Ealley EL, Nevalainen MT, Rui H: Stat5 promotes homotypic adhesion and inhibits invasive characteristics of human breast cancer cells. Oncogene 2005, 24:746-760.

19. Sultan AS, Brim H, Sherif ZA: Co-overexpression of Janus kinase 2 and signal transducer and activator of transcription 5 a promotes differentiation of mammary cancer cells through reversal of epithelial-mesenchymal transition. Cancer Sci 2008, 99:272-279.

20. Nouhi Z, Chughtai N, Hartley S, Cocolakis E, Lebrun JJ, Ali S: Defining the role of prolactin as an invasion suppressor hormone in breast cancer cells. Cancer Res 2006, 66:1824-1832.

21. Sato T, Tran TH, Peck AR, Girondo MA, Liu C, Goodman CR, Neilson LM, Freydin B, Chervoneva I, Hyslop T, Kovatich AJ, Hooke JA, Shriver CD, Fuchs SY, Rui H: Prolactin suppresses a progestin-induced CK5-positive cell population in luminal breast cancer through inhibition of progestindriven BCL6 expression. Oncogene 2013. In Press.

22. Gass S, Harris J, Ormandy C, Brisken C: Using gene expression arrays to elucidate transcriptional profiles underlying prolactin function. J Mammary Gland Biol Neoplasia 2003, 8:269-285.

23. Harris J, Stanford PM, Sutherland K, Oakes SR, Naylor MJ, Robertson FG, Blazek KD, Kazlauskas M, Hilton HN, Wittlin S, et al: Socs2 and elf5 mediate prolactin-induced mammary gland development. Mol Endocrinol 2006 20:1177-1187

24. Hou Z, Bailey JP, Vomachka AJ, Matsuda M, Lockefeer JA, Horseman ND: Glycosylation-dependent cell adhesion molecule 1 (GlyCAM 1) is induced by prolactin and suppressed by progesterone in mammary epithelium. Endocrinology 2000, 141:4278-4283.

25. Naylor MJ, Oakes SR, Gardiner-Garden M, Harris J, Blazek K, Ho TW, Li FC, Wynick D, Walker AM, Ormandy CJ: Transcriptional changes underlying the secretory activation phase of mammary gland development. $\mathrm{Mol}$ Endocrinol 2005, 19:1868-1883.

26. Ormandy CJ, Naylor M, Harris J, Robertson F, Horseman ND, Lindeman GJ, Visvader J, Kelly PA: Investigation of the transcriptional changes underlying functional defects in the mammary glands of prolactin receptor knockout mice. Recent Prog Horm Res 2003, 58:297-323.

27. Perotti C, Liu R, Parusel CT, Bocher N, Schultz J, Bork P, Pfitzner E, Groner B, Shemanko CS: Heat shock protein-90-alpha, a prolactin-STAT5 target gene identified in breast cancer cells, is involved in apoptosis regulation. Breast Cancer Res 2008, 10:R94.

28. Fiorillo AA, Medler TR, Feeney YB, Wetz SM, Tommerdahl KL, Clevenger CV: The prolactin receptor transactivation domain is associated with steroid hormone receptor expression and malignant progression of breast cancer. Am J Pathol 2013, 182:217-233.

29. Sharma NL, Massie CE, Ramos-Montoya A, Zecchini V, Scott HE, Lamb AD, Macarthur S, Stark R, Warren AY, Mills IG, Neal DE: The androgen receptor induces a distinct transcriptional program in castration-resistant prostate cancer in man. Cancer Cell 2013, 23:35-47.

30. Yoshimura A, Ohkubo T, Kiguchi T, Jenkins NA, Gilbert DJ, Copeland NG, Hara T, Miyajima A: A novel cytokine-inducible gene CIS encodes an SH2-containing protein that binds to tyrosine-phosphorylated interleukin 3 and erythropoietin receptors. EMBO J 1995, 14:2816-2826.

31. Neilson LM, Zhu J, Xie J, Malabarba MG, Sakamoto K, Wagner KU, Kirken RA, Rui H: Coactivation of Jak1 positively modulates prolactin-Jak2 signaling in breast cancer: recruitment of ERK and Stat3 and enhancement of Akt and Stat5a/b pathways. Mol Endocrinol 2007, 21:2218-2232.

32. Liu X, Robinson GW, Wagner KU, Garrett L, Wynshaw-Boris A, Hennighausen $L: S t a t 5 a$ is mandatory for adult mammary gland development and lactogenesis. Genes Dev 1997, 11:179-186.

33. Tran TH, Utama FE, Lin J, Yang N, Sjolund AB, Ryder A, Johnson KJ, Neilson LM, Liu C, Brill KL, et al: Prolactin inhibits BCL6 expression in breast cancer through a Stat5a-dependent mechanism. Cancer Res 2010, 70:1711-1721.

34. Wagner KU, Krempler A, Triplett AA, Qi Y, George NM, Zhu J, Rui H: Impaired alveologenesis and maintenance of secretory mammary epithelial cells in Jak2 conditional knockout mice. Mol Cell Biol 2004, 24:5510-5520.

35. Grimley PM, Dong F, Rui H: Stat5a and Stat5b: fraternal twins of signal transduction and transcriptional activation. Cytokine Growth Factor Rev 1999, 10:131-157.

36. Bernaciak TM, Zareno J, Parsons JT, Silva CM: A novel role for signal transducer and activator of transcription $5 \mathrm{~b}$ (STAT5b) in beta1-integrin-mediated human breast cancer cell migration. Breast Cancer Res 2009, 11:R52.

37. Fox EM, Bernaciak TM, Wen J, Weaver AM, Shupnik MA, Silva CM: Signal transducer and activator of transcription $5 b, c-S r c$, and epidermal growth factor receptor signaling play integral roles in estrogen-stimulated proliferation of estrogen receptor-positive breast cancer cells. Mol Endocrinol 2008, 22:1781-1796.

38. Tang JZ, Zuo ZH, Kong XJ, Steiner M, Yin Z, Perry JK, Zhu T, Liu DX, Lobie PE: Signal transducer and activator of transcription (STAT)-5A and STAT5B differentially regulate human mammary carcinoma cell behavior. Endocrinology 2010, 151:43-55.

39. Nakajima H, Brindle PK, Handa M, Ihle JN: Functional interaction of STAT5 and nuclear receptor co-repressor SMRT: implications in negative regulation of STAT5-dependent transcription. EMBO J 2001, 20:6836-6844.

40. Ciarloni L, Mallepell S, Brisken C: Amphiregulin is an essential mediator of estrogen receptor alpha function in mammary gland development. Proc Natl Acad Sci U S A 2007, 104:5455-5460.

41. Esseghir S, Kennedy A, Seedhar P, Nerurkar A, Poulsom R, Reis-Filho JS, Isacke CM: Identification of NTN4, TRA1, and STC2 as prognostic markers in breast cancer in a screen for signal sequence encoding proteins. Clin Cancer Res 2007, 13:3164-3173.

42. Cizkova M, Cizeron-Clairac G, Vacher S, Susini A, Andrieu C, Lidereau R, Bieche I: Gene expression profiling reveals new aspects of PIK3CA mutation in ERalpha-positive breast cancer: major implication of the Wnt signaling pathway. PLoS One 2010, 5:e15647.

43. Ruiz-Garcia E, Scott V, Machavoine C, Bidart JM, Lacroix L, Delaloge S, Andre F: Gene expression profiling identifies Fibronectin 1 and CXCL9 as candidate biomarkers for breast cancer screening. Br J Cancer 2010, 102:462-468.

44. Nam JM, Onodera Y, Bissell MJ, Park CC: Breast cancer cells in three-dimensional culture display an enhanced radioresponse after coordinate targeting of integrin alpha5beta1 and fibronectin. Cancer Res 2010, 70:5238-5248.

45. Gupta GP, Nguyen DX, Chiang AC, Bos PD, Kim JY, Nadal C, Gomis RR, Manova-Todorova K, Massague J: Mediators of vascular remodelling co-opted for sequential steps in lung metastasis. Nature 2007, 446:765-770.

46. Wysolmerski JJ, Philbrick WM, Dunbar ME, Lanske B, Kronenberg H, Broadus $\mathrm{AE}$ : Rescue of the parathyroid hormone-related protein knockout mouse 
demonstrates that parathyroid hormone-related protein is essential for mammary gland development. Development 1998, 125:1285-1294.

47. Li J, Karaplis AC, Huang DC, Siegel PM, Camirand A, Yang XF, Muller WJ, Kremer R: PTHrP drives breast tumor initiation, progression, and metastasis in mice and is a potential therapy target. J Clin Invest 2011, 121:4655-4669.

48. Kohno N, Kitazawa S, Fukase M, Sakoda Y, Kanbara Y, Furuya Y, Ohashi O, Ishikawa Y, Saitoh Y: The expression of parathyroid hormone-related protein in human breast cancer with skeletal metastases. Surg Today 1994, 24:215-220.

49. Guise TA, Yin JJ, Thomas RJ, Dallas M, Cui Y, Gillespie MT: Parathyroid hormone-related protein (PTHrP)-(1-139) isoform is efficiently secreted in vitro and enhances breast cancer metastasis to bone in vivo. Bone 2002, 30:670-676.

50. Graham JD, Hunt SM, Tran N, Clarke CL: Regulation of the expression and activity by progestins of a member of the SOX gene family of transcriptional modulators. J Mol Endocrinol 1999, 22:295-304.

51. Liu P, Ramachandran S, Ali Seyed M, Scharer CD, Laycock N, Dalton WB, Williams H, Karanam S, Datta MW, Jaye DL, Moreno CS: Sex-determining region $\mathrm{Y}$ box 4 is a transforming oncogene in human prostate cancer cells. Cancer Res 2006, 66:4011-4019.

52. Nakamura Y, Yasuoka H, Tsujimoto M, Yang Q, Imabun S, Nakahara M, Nakao K, Nakamura M, Mori I, Kakudo K: Flt-4-positive vessel density correlates with vascular endothelial growth factor-d expression, nodal status, and prognosis in breast cancer. Clin Cancer Res 2003, 9:5313-5317.

53. Dagvadorj A, Kirken RA, Leiby B, Karras J, Nevalainen MT: Transcription factor signal transducer and activator of transcription 5 promotes growth of human prostate cancer cells in vivo. Clin Cancer Res 2008, 14:1317-1324

54. Johnson KJ, Peck AR, Liu C, Tran TH, Utama FE, Sjolund AB, Schaber JD, Witkiewicz AK, Rui H: PTP1B suppresses prolactin activation of Stat5 in breast cancer cells. Am J Pathol 2010, 177:2971-2983.

55. da Huang W, Sherman BT, Lempicki RA: Systematic and integrative analysis of large gene lists using DAVID bioinformatics resources. Nat Protoc 2009, 4:44-57.

56. da Huang W, Sherman BT, Lempicki RA: Bioinformatics enrichment tools: paths toward the comprehensive functional analysis of large gene lists. Nucleic Acids Res 2009, 37:1-13.

57. Ertel A, Dean JL, Rui H, Liu C, Witkiewicz AK, Knudsen KE, Knudsen ES: RB-pathway disruption in breast cancer: differential association with disease subtypes, disease-specific prognosis and therapeutic response. Cell Cycle 2010, 9:4153-4163.

doi:10.1186/1476-4598-12-59

Cite this article as: Sato et al:: Global profiling of prolactin-modulated transcripts in breast cancer in vivo. Molecular Cancer 2013 12:59.

\section{Submit your next manuscript to BioMed Central and take full advantage of:}

- Convenient online submission

- Thorough peer review

- No space constraints or color figure charges

- Immediate publication on acceptance

- Inclusion in PubMed, CAS, Scopus and Google Scholar

- Research which is freely available for redistribution

Submit your manuscript at www.biomedcentral.com/submit
() Biomed Central 